\title{
Reflexiones sobre el proceso de canonización de Monseñor Romero
}

\section{Jon Sobrino \\ Centro de Reflexión Teológica, San Salvador.}

Este año celebramos el XVIIl Aniversario del martirio de Monseñor Romero cuando ya está en marcha el proceso oficial de su canonización. En este escrito qucremos reflexionar sobre dicho proceso, pero no tinto sobre lo que tiene de procedimiento eclesiástico, sino sobre su significado actual para la Iglesia y el pueblo. Lo vamos a hacer enunciando y comentando seis breves proposiciones.

1. Antes de la canonizacion oficial ya ha tenido lugar la canonización popular de Monseñor Romero. El hecho es evidente, y de esta canonización popular vive la canonización oficial.

Aunque sea conocido, hay que recordarlo porque es fundamental para reflexionar adecuadamente sobre la canonización oficial de Monseñor. A los pocos días de su asesinato, don Pedro Casildáliga - profela ccrlero y porlador de huenas nuevas- cscribió, agradecido, su conocido pocma "San Romcro de América". La realidad tomaba la palabra en la pluma de don Pedro y pronunciaba la expresión que reserva para momentos de singular importancia: "santo". Y es que en un mundo como el nuestro, de crueldad y mentira, de vez en cuando hace su aparición lo humano cabal, la compassión sin componendas, la verdad sin segundas intenciones, el compromiso hasta el final. Y entonces, con sorpresa, con gozo - también con el sentimiento de ser interpelados- y solvre todo con agradecimiento, a los seres humanos se nos escapa la palabra "santo".

El pucblo - su pobrería" sobre todo- lo vio así desde el principio. Sin mucha ciencia ni derecho canónico, pero con un gran sensus fidci, con el sentido innato que discierne entre lo bueno y lo malo, lo auléntico y lo falaz, que discierne sobre todo la presencia de Dios en nuestro mundo, enseguida llamó a Monseñor Romero profeta, pastor y mártir. Certeramente expresó desde el principio esta triple realidad con palabras como éstas: "Monscñor Romero dijo la 
verdad, nos defendió a nosotros de pobres y por ello lo mataron". Y dio un paso más, verdaderamente audaz si no se da por supuesto, aceptando con entusiamo que Monseñor Romero era santo, y además un santo suyo, como no lo son otros santos, más distantes que Monseñor en el espacio y en el tiempo.

Este es el hecho mayor. En vida "el pueblo te hizo santo", dice don Pedro. Ahora ese mismo pueblo lo quiere como a un santo, pero no sólo como a un santo "de altar", que intercede y concede favores, sino también como a un santo "de familia", a quien se le quiere entrañablemente. De ahí también —de nuevo don Pedro- que "scría pecado qucrer canonizarlo".

De santo salvadoreño Monseñor se convirtió muy pronto en santo universal. "Les tengo una mala noticia", dijo alguien venido de Francia. "Monseñor Romero ya no es de ustedes. Es de todos". Y así es. Católicos, cristianos de todas las confesiones, incluso algunos miembros de comunidades y asambleas evangélicas, lo hacen suyo. $Y$ también marxistas y hasta agnósticos. $Y$ es que ser santo es ser cabal, y esto lo capta bien y lo agradece mucha gente en todo el mundo.

$Y$ por lo que loca al tiempo, los años transcurridos desde su asesinato no han llevado a "descanonizar" a Monseñor, como pudiera haber sucedido, sino que, por el contrario, lo canonizan más y con lodas las señales que acompañan a una canonización popular. Canonizado está ya el "liempo": no hace falta explicar qué quiere decir "el 24 de marzo", como no hace falta explicar qué quiere decir el 24 de diciembre o aquí en El Salvador el 15 de septiembre. Canonizado está también el "lugar", convertido, como Belén o el Calvario, en lugar sagrado de peregrinación. $Y$ así no hace falta explicar qué significa "el hospitalito", a donde llegan peregrinos con devoción sentida - probablemente mayor que con la que llegan a olros santuarios- pues alli se respira todavía profecía, buena noticia y martirio. Canonizado está su "recuerdo" con la publicación de sus escrilos, homilias, discursos, diario, traducidos a numerosos idiomas, y con la publicación de olros muchos escrilos sobre él, afiches, estampas, poesías, corridos, óperas, películas, con innumerables instituciones que llevan su nombre... No podemos asegurarlo con cerleza, pero Monseñor Romero bien pudiera ser el márlir y personaje religioso de nuestra época que ha lenido mayor impacto. En la abadía de Wesıminster su figura estará desde el próximo mes de julio como uno de los diez márlires de este siglo.

Y la piedad popular, a su modo, pero certeramente, le adjudica lo que es lípico de los santos canonizados: Monseñor Romero intercede por los necesitados, hace milagros, como lo dicen las placas sobre su lumba y los innumerables papelitos, escrilos con letra de pobres, que, lamentablemente, no han sido conservados. Una sencilla campesina de Guazapa contaba un milagro que le había hecho Monseñor, y añadia, orgullosa, "éste es el primer milagro que hizo Monseñor Romero" - como en el evangelio de Juan. Qué milagros sean ésos, no es pregunta muy importante ahora. Lo importante es que con cllos la genle expresa que asi 
como Monseñor en vida estuvo en su favor, así lo sigue estando ahora: hace favores, a los pobres sobre todo, cuando muy poca gente se preocupa de ellos.

En conclusión, la canonización popular de Monseñor Romero es un hecho evidente. Ocurre como en las canonizaciones por aclamación popular del cristianismo primilivo, pero añadiendo un matiz importante: Monseñor Romero es aclamado porque es querido, y es querido porque él en verdad amó a su pueblo.

Ese es el hecho mayor. $Y$ digamos para terminar que esta "canonización popular" es lo que da sentido a la canonización oficial. Ambas responden a distintos ámbitos de realidad y ambas son necesarias, pero no son lo mismo. Lo fundamental y primigenio es el conocimiento que tiene el pueblo de la presencia de Dios entre nosoltos, en acontecimientos y personas, lo cual va acompañado de cariño, entusiasmo y esperanza. Lo derivado es el re-conocimiento que hace la lglesia jerárquica, que reglamenta - canon significa regla- el cntusiasmo y garantiza que no se cometan abusos.

2. El proceso de canonización oficial de Monseñor Romero no es evidente. Ha tenido que superar obstáculos importantes dentro de la Iglesia y de la sociedad civil. Es una victoria.

Más adelante analizaremos en positivo el significado del proceso olicial de canonización, pero comencemos diciendo que el de Monseñor Romero no ha sido nada evidenle. Recordemos algunos datos importantes.

a) En vida. a diferencia, por ejemplo, de lo ocurrido con la madre Teresa de Calcuta, - acogida y venerada por iglesias y gobiernos- Monseñor Romero no fue bien visto, en general, por la jerarquía eclesiástica. Es bien conocido que aquí, en El Salvador, Monseñor fue alacado por todos los obispos salvadoreños con la excepción de Mons. Rivera. Esto puede parecer hoy sorprendente y desconcertante, pero en su día fue de dominio público. Varias veces, sus hermanos obispos se pronunciaron contra él. Cuando junto con Mons. Rivera publicó su tercern carta pastoral sobre "La Iglesia y las organizaciones populares" - magnífica carta tenida internacionalmente cono pionera sobre el tema-, los otros cuatro obispos publicaron un breve mensaje en el que la contradecian prácticamentc en todo. El mismo Monseñor dejó escrito en su diario espiritual, un mes antes de ser asesinado, que uno de sus grandes problemas, junto al miedo a la muerle que preveía cercana y su vida espiritual -preocupación ésta de alma delicada-, eran sus hermanos obispos. “Otro aspecto de mi consulta espiritual... fue mi situación conflictiva con los otros obispos" (25 de febrero de 1980). De hecho, sólo Mons. Rivera asistió a su entierro. Y hasta el día de hoy, algunos de ellos siguen expresándose en su contra. En la reciente visita de Juan Pablo II a El Salvador, en 1996, cuando el papa pregunló a los obispos qué pensaban de la canonización de Monseñor Romero, el entonces presidente de la conferencia episcopal respondió que había sido responsable de 70,000 muertos. 
Y en el Vaticano las cosas no fueron muy diferentes. El nuncio estaba en su contra. En la congregación para los obispos se pensó seriamente en destituirlo o anularlo, dejándolo como figura decorativa con un administrador sede plena con plenos poderes. En poco más de un año el Vaticano envió tres visitadores apostólicos - medida extrema que normalmente se utiliza cuando hay serios y graves problemas en una diócesis. Con el papa Pablo VI le fue bien, y salió confortado de su visita en 1977, pero la primera visita a Juan Pablo Il fue dolorosa, pues el papa no pareció apreciar la gravedad de la persecución a la Iglesia salvadoreña y más bien le puso en guardia de hacer el juego al comunismo. Muy distinta será su actitud posterior-pero, en aquel entonces, Monseñor Romero dejó el Vaticano triste y lloroso, buscando consuelo en el cardenal Pironio y en el padre Arrupe, experlos también en incomprensiones vaticanas.

Después de su asesinato - aunque no fuese más que por pudor- la lesis oficial, que sospechaba del ministerio de Monseñor, se hizo más benigna, pero en definitiva seguía siendo de desaprobación hacia su persona: Monseñor habria sido una buena persona, pero ingenuo y sin personalidad, de lo cual otros se aprovecharon para manipularlo, sobre todo los jesuilas. La verdad es que Monseñor Romero, con su fidelidad a Medellín y Puebla, al evangelio y a los pobres, introducía el conflicto en la lglesia, sacaba a luz actiludes eclesiales poco coherentes y con su cjemplo interpelaba a la honradez. Por ello, la oposición fue honda y las cosas sólo cambiaron con el viaje de Juan Pablo 11 a El Salvador en 1983. En aquellos años, nada hacía pensar que la Iglesia oficial estuviese interesada en canonizar a Monseñor.

b) La segunda dificultad para la canonización, no decisiva, pero que sí hay que tener en cuenta de alguna forma, proviene del conflicto que aquélla puede generar con gobiernos y otros poderes, conflictos que, en la medida de lo posible, se desean evitar. En el caso de Monseñor - y dada la cercanía de los hechos- la canonización es objetivamenle una provocación -inevitable, no antojadiza- para muchos de los poderosos en El Salvador. En efecto, al canonizarlo, se está proponiendo como cristiano y como ser humano ejemplar, digno de imitación y beneficioso para el pais, a quien ha sido odiado y difamado hasta el extremo.

Y este conflicto se agrava al canonizarlo como mártir, pues "mártir" supone haber sido asesinado, y ello remite por necesidad a sus verdugos. Dada la cercanía de los hechos, muchos de los responsables intelectuales y materiales del asesinato y muchos de los que lo apludieron siguen vivos - y son personas prominentes en el país y en el partido en el gobierno. La Comisión de Naciones Unidass lo dijo lapidariamente en el Informe de la Verdad: "El exmayor Roberto D'Aubuisson dio la orden de asesinar al arzobispo y dio instrucciones precisas a miembros de su entorno de seguridad, actuando como 'escuadrón de la muerte', de organizar y supervisar la ejecución del asesinato". Mons. Rivera lo recordó 
con valentía poco antes de las elecciones presidenciales de marzo de 1994, relacionándolo con el partido en el poder: "Lo quieran o no, la sombra de este crimen sacrílego persigue a quienes, aun después de catorce años, siguen impenitentes idolatrando al hombre que quiso resolver los problemas de El Salvador a sangre y fuego".

En la actualidad, esos mismos grupos siguen sin reconocer las virtudes de Monseñor Romero y siguen repitiendo que fue nefasto, que sobrepasó el límite de to religioso, como dice el candidato de ARENA. Además, un miembro del gobicrno aclual ha dicho sin tapujos: "Mons. Romero: un desastre. Mayor D'Aubuisson: un mártir". Siguen, pues, aclamando al responsable de su asesina10, sin expresar ningún tipo de arrepentimicnto ni reparación por lo ocurrido. Difaman o silencian a la víctima y ensalzan y aclaman al asesino. De ahí la conclusión de Mons. Rosa: "Los más declarados adversarios de la canonización de Monseñor Romero son los mismos que le hostigaron en vida, que le escribian cartas anónimas, acusándolo de ser comunista, y que por desgracia continúan hostigándolo incluso ahora".

Canonizar hoy a la víctima significa juzgar automáticamente -aunque despućs sc otorgue perdón- a sus asesinos. Esto, en sí mismo, no facilita el proceso. Es claro que, en estos tres últimos años, la nuncialura y algunos obispos salvadoreños han dado gran importancia a la armonia y a las buenas relaciones entre la Iglesia y el Estado - y de ahí también que se invoque con ligereza la tesis del olvido-, aunque también hay que recalcar y agradecer que la comisión diocesana encargada del proceso haya dado muestras de independencia y firmeza al investigar el asesinato.

Dada la cercanía de los hechos y la actual siluación del país, la canonización de Monseñor "chirría" objelivamente. Hasta el dia de hoy, ni los gobiernos, ni los políticos habituales, ni la Fuerza Armada, ni la oligarquía, han pedido perdón por cómo lo trataron, ni mucho menos han mostrado agradecimiento por Monseñor. (Y habría quc recordar también la oposición del gobiemo norteamericano, sus presiones ante el Vaticano para callar a Monseñor - aunque para una superpotencia esta injusticia sea peccuta minuta.)

A pesar de todo, la comisión sigue trabajando con decisión y el proceso sigue adelante. Lo que hace dieciocho años parecía impensable se ha hecho posible, y lo imporante es saber por qué.

3. El proceso de cunonización ha sido posible por la convergencia de varios factores. Dos de ellos, externos a Monseñor Romero, son el apoyo personal de Juan Pablo II y su peso mundial.

Más allá de cumplir a satisfacción - por lo que se conoce- los requisilos formales que se exigen en el proceso (constatación de su ortodoxia y sus virtu- 
des, recopilación de testimonios en pro y en contra, evitar el culto público, elc.), éste ha sido posiblitado por varias cosas.

En primer lugar, Juan Pablo II cambió de postura hacia Monseñor y lo ha expresado claramente con sus hechos. Independientemente de las razones (el impacto personal de su martirio ante todo, mejor información, lectura de sus escritos), el hecho es innegable. En su vista a El Salvador en 1983, por deseo propio - y en contra del deseo del gobierno- visitó la tumba de Monseñor en caledral, visila que había sido excluida del programa oficial. La folografía de Karol Wojlila - lo formulamos así porque en ella aparece el ser humano antes que cl papa- rezando ante la tumba de Monseñor Romero y las palabras con que se refirió a él como "celoso pastor que dio la vida por su pucblo", son un testimonio personal entrañable, $y$, además, supuso un cambio radical de dirección en el Vaticano: el Papa lo había alabado y ya no se podía decir impunementc dentro de la lglesia que Monseñor había sido marxista, colaborador de la guerrilla, lonto útil manipulado... Y cuando en 1994 Mons. Rivera decidió poner en marcha el proceso diocesano, reconoció que ello no guslaba en algunos dicasterios valticanos, pero que Juan Pablo Il, personalmente y a pesar de ello, dio el visto bueno.

La postura del Papa nos parece que ha sido decisiva como condición sine qua non para que se inicie y prosiga el proceso. Al nivel eclesiástico, de curias y dicasterios, ya no se puede ir contra Monseñor. $Y$ más importante, a nivel eclesial, el del pueblo de Dios, el afecto del papa a Monseñor ha lortalecido el del pueblo. En su segunda visita en 1996, sólo hubo un aplauso público y fue cuando Juan Pablo II recordó en catedral a Monseñor Romero "brutalmente asesinado mientras ofrecía el sacrificio de la inisa". Para que haya prosperado el proceso de canonización oficial, la postura del Papa no ha sido del todo suficiente, pero sí ha sido positiva y necesaria.

Otra cosa que ha forzado objetivamente a comenzar el proceso es el impacto mundial, duradero y en alumenlo de Monseñor. Cuando murió la madre Teresa de Calcula surgieron voces pidiendo su pronla canonización. Con Monseñor Romero no ocurrió lo mismo y no se habló de canonizacion, pero se desencadenó un ingente movimiento de admiración, agradecimiento, cariño y reconocimiento de su necesidad para el mundo. Comenzó muy pronto lo que podemos llamar el "romerismo", la tradición generada por Monseñor, del mismo modo como Francisco de Asís generó el "franciscanismo".

En la conciencia colectiva de este fin de siglo, más o menos por supuesto, Monseñor eslá presente en el mundo conno suspiro de alivio de que lo humano es posible, como agradecimiento de que hay seres humanos que nos salvan y nos redimen de nuestro cgoísmo y pequeñez, que son como aquel Jesús ell quiell podemos tener "fijos los ojos" en nuestras aflicciones, y también en nuestras decisiones de enrumbar este mundo en una dirección muy distinta a la actual. 
Es sabido, pero no hay que trivializarlo sino valorarlo grandemente. En el último sínodo para las Américas, celebrado en Roma, los obispos discutieron si los cristianos que habían sido asesinados por la defensa de la justicia debian ser llamados "mártires" o sólo "testigos", reservando el término "mártir" para quien moría explícilamente por causa de la fe -disquisiciones y casuística a las que somos dados los humanos. Pero cuando Mons. Gregorio Rosa habló de Mons. Romero, de su persona, de su profecía y de su martirio, se olvidó la casuística y en el aula sinodal resonó el mayor y más prolongado aplauso de todo el sínodo.

Monseñor Romero ha impactado a muchos obispos personalmente, sobre todo a quienes eslán en situaciones parecidas a las suyas, como lo reconoce don Samuel Ruiz. En otros hay respeto por ese hermano suyo salvadoreño, y hasta sano "orgullo de clase" de que haya obispos como ćl, profelas, evangelizadores, sin miedo y con esperanza.

Monseñor Romero siguc causando un impacto mundial —más allá de las incomprensiones y pequeñeces de algunos- y ese impacto tiene un peso objetivo que fuerza a su canonización. ¿Cómo podría la Iglesia decir al mundo que ignora a personas como Monseñor, que lo hace pasar desapercibido? En la conciencia colectiva de esta humanidad nuestra esto es hoy - atortunadamentemuy difícil, casi imposible.

\section{Lo que ha forzado, en definitiva, a la canonización de Monseñor Romero} es su sanfidad real, muy necesaria en nuestro mundo y en mesestra Iglesia.

A este impacto mundial ha ayudado, indudablemente, una serie de faclores poco comunes. Monseñor fue figura pública en un pais y en una Iglesia que fueron nolicia mundial durante mucho tiempo: masacres, sacerdotes asesinados, "haga patria mate un cura", su carta a Carter, sus últimas palabras, "en nombre de Dios, jcese la represión!", y tanıas otras cosas. Pero más allá de esio, y leniendo en cuenta que en la historia cambian unas cosas, sí, pero otras permanecen, como permanece la condición humana, la verdad es que hay algo en Monseñor que fuerza a mantenerlo vivo y presentarlo como ser humano y crisliano cabal —eso significa cunonización lambićn cl dia de hoy. Podemos decir que en Monseñor Romero hay algo de mela-paradigmático, más allá de los cambios de paradigmas - lan invocados hoy y no siempre para hacer lo que hay que hacer.

Lo que se impone de Monseñor a través de los liempos es su autenticidad, honradez, compasión... Pero, aunque verdaderas, estas palabras sólo cobran su hondura real desde sus desilinalarios direclos, aquellos que llenaron su corazón y aquellos que lo acogieron en su corazón: los pobres de este mundo. Como hemos dicho antes, ellos definen a Monseñor Romero deside la verdad, la compasión y la fidelidad. Y esio es lo que se impone de Monseñor hasla el día de hoy. 
En un mundo de mentiras -ayer como hoy-, ayer más burdamente en las declaraciones de gobiernos (el nuestro y el de Estados Unidos), fuerzas armadas, políticos y oligarquías, hoy más sutilmente, con concesiones a una mayor liberlad de expresión, pero con el encubrimiento fundamental de la verdad (la mitad de la población del mundo eslá amenazada de pobreza), la verdad es como "el agua limpia que baja de los montes", como decía Rutilio Grande. Esa verdad, mil veces negada, oprimida, manipulada en favor de los opresores y en contra de los oprimidos, eso es lo que significa hasta el día de hoy Monseñor Romero, sin que -en plena euforia de democracia - se haya encontrado un símbolo mejor de la verdad que el Monseñor profeta.

En un mundo de crueldad -ayer como hoy-, ayer más burdamente con masacres aberrantes, hoy con la pobreza colidiana (el producto intemo bruto en El Salvador es menor que el de antes de la guerra), con la violencia colidiana (diez mil fueron los muertos violentamente en 1995 y olros diez mil en 1996) y con el desprecio cotidiano a las mayorías populares, la compasión, el amor y la juslicia son como bálsamo que cura heridas y anima a trabajar. Esa compasión a los pobres de este pueblo es lo que hasta el día de hoy expresa Monseñor Romero, sin que "el juego de la democracia", ni los Jatos macroeconómicos, ofrezcan algo mejor que el Monseñor justo y consolador.

En un mundo dividido y antagónico, hecho de ricos epulones (las Iransnacionales en todo el mundo, el capital financiero en nuestro pais) y de pobres lázaros que esperan migajas (el rebalse); en un mundo inhumano en el cual no interesa la familia humana, sino el propio interés, en el que no hay líderes que guien al pueblo, sino que se aprovechan de él y lo desuellan, como dice Oseas, Monseñor Romero expresa la cercanía, el conocimiento de sus ovejas, como buen pastor. Monseñor Romero sigue siendo el gran conocedor de los pobres de este pueblo, y ellos lo conocen a él. Monseñor sigue siendo hasta el dia de hoy - sin que se vislumbre ningún candidato que lo reemplace- la voz de los sin voz.

En un mundo alienado, infantilizado por los modernos y nada antiguos "circenses", decidido a industrializarlo todo (naluraleza, vacaciones, deporte, música, moda, funerales de celebridades...), haciendo bueno el dicho de que business is business, y que, por lo tanto, está permitido desnaturalizarlo todo para comercializar y dinerizarlo todo, Monseñor Romero expresa que es posible vivir con gozo, en el encuentro de unos con olros, en aquellos encuentros suyos con los campesinos, en los cantones o en la curia arzobispal. Es el gozo que se le escapó en estas palabras: "Con este pueblo no cuesla ser buen pastor".

En un mundo de componendas, de evitar tensiones y confliclos - aunque los exija la realidad-, de no tomar nada totalmente en serio, a no ser el propio interés, de no animar al compromiso fiel, aquello que exige la ética y la fe, y aquello que, además. lleva a la verdadera felicidad, Monseñor Romero expresa 
que es posible ser humano y ser cristiano compromelido y fiel "hasta el final". Eso fue su martirio.

Y una última palabra. En un mundo en que se ignora, peor aún, en que se trivializa y banaliza la le en el misterio de Dios, Monseñor sigue siendo el creyente en el Dios de Jesús, el Dios de la vida, el Dios de las víctimas, "el Dios en quien el pobre encuentra compasión". Monseñor Romero es el creyente que ofrece a lodos al Dios de Jesús para que los humanos seamos más que humanos, como decía Agustín.

De todo esto ticne necesidad el mundo y tambićn la Iglesia. En una Iglesia con exceso de verticalismo y autorilarismo, Monseñor aparece como un obispo popular y sin populismo. En una Iglesia con miedo en su interior, donde cucstil decir con sinceridad lo que se piensa, Monscñor aparece como pastor hermano, abajado a todos y gozoso de estar con todos. En una Iglesia distanciada a veces de la realidad, viviendo en el mundo que se fabrica y que muchas veces no coincide con el mundo real, Monseñor aparece como un creycnte encarnado. En una Iglesia que, eficazmente, da muchas veces ultimidad a la doctrina y a la ley, Monscñor aparece como el servidor del pueblo, el defensor de la vida de los pobres, el compasivo ante las víctimas, y en ello y en su Dios pone él la ultimidad.

Todo esto lo capla muy bien el sensus fidelium. Se imponc la canonización de Monseñor Romero y su presentación en la doble dimensión de santo canonizado. Santo es el intercesor. quien está en favor nuestro, intercediendo ante Dios en lenguaje de la tradición, quien da ánimo, fuerza, vida y csperanza en lenguaje hislórico. Y santo es el modelo, quien nos muestra el camino a seguir, con sus virtudes eximias en lenguaje de la Iradición, con su ser salvadoreño y cristiano cabal en lenguajc hislórico.

Y quizás una úlıima cosa, más visible en Monseñor Romero que ell otros santos ya distantes. Santo es quien produce gozo, buena noticia en un mundo de malas realidades. Más allá de su utilidad como intcrcesor y modelo, santo es quien hace presente la ternura de Dios en este mundo, ante lo cual sólo cabe decir "gracias". De Jesús se dijeron cosas sublimes, pero lo que en defintiva le define son aquellas palabras de los Hechos: "Pasó haciendo el bien y consolando a todos los afligidos". O aquellas otras de la carta a Tílo: "Ha aparecido la benignidad de Dios". De Monseñor Romero unos, como Ignacio Ellacuría, dijeron que era "un enviado de Dios para salvar a su pueblo". Otros dijeron que era "una buena noticia de Dios para los pobres".

A este Monseñor hay que ponerlo en lo alto para que sea luz que ilumine las linieblas y sca ánimo que venza la indiferencia. La canonización de Monseñor Romero se impone. Parafraseando a Jesús, "si la lglesia callara, las piedras hablarian". 
5. La canonización oficial, como todo lo humano, tiene también sus peligros.

En este caso, el peligro consitiría en canonizar a un Monseñor Romero desdibujado y en que la Iglesia lo acaparase indebidamente.

Todo lo humano es ambivalente, está abierto a la gracia, pero es también proclive a la pecaminosidad. De esto no hay que sorprenderse y por ello hablamos también de los posibles peligros de esta canonización.

a) Es difícil detener el proceso de canonización de Monseñor Romero, pero se lo puede desdibujar y cooptar. Desde este punto de vista, cl peligro consistiría en canonizar a un Monseñor bueno, piadoso, sacerdotal, pero en definitiva a un Monseñor aguado. Consistiria en quilarle las aristas y el fuego que tuvo como profeta, y el quitarle las entrañas de misericordia que tuvo como buen samaritano.

Siempre existe el peligro de enlender la sanlidad, como si, en defintiva, ésta se expresase mejor en la cercanía a Dios, y de entender a Dios como lo que estuviese más allá de lo humano o en competencia con lo humano, como si Dios fuese celoso de hombres y mujeres. Es el peligro que expresan eslas palabras ya clásicas: "Como no son de la lierra creen que son del cielo. Como no son de los hombres creen que son de Dios. Como no aman a los hombres creen que anan a Dios".

Si no en esta forma burda, si en otras más sutiles, en la Iglesia algunos piensan que para santificar a un ser humano es más seguro acercarlo a Dios y distanciarlo de los humanos, que acercarlo a ellos, pues esto los distanciaría de Dios - y, así, desde este presupuesto se podría canonizar a un Monseñor Roinero aguado, no al verdadero Monseñor.

Es evidente que Monseñor fue hombre de Dios, creyenle, devolo; que lue sacerdote, dispensador de los misterios de Dios; que fue arzobispo, cuidador de la fe y de las cosas santas de su pueblo. Pero a eso hay que añadir $-\mathrm{y}$ hacer de ello cosa central- que Monseñor fue un insigne salvadoreño que por eso se encarnó en una realidad de conflicto y muerte. Que fue defensor de los pobres y por eso fuc amado y venerado por ellos. Que lue profela, denunciador y desenmascarador de militares, oligarcas, gobernantes y políticos y por eso lue odiado por ellos. Que fue voz de los sin voz y por eso lue voz conlra los que lienen demasiadi voz. Que fue creyente y hombre de Dios y por eso fue encmigo acérrimo de los idolos. En suma, es evidenle que el verdadero Monseñor vivió todo para Dios y todo para la justicia. Ese fue el Monseñor Romero total, el "verdadero" Monseñor. $Y$ ese Monseñor es el que el pueblo espera que sea canonizado, el que sea presentado como protector y modelo de este pueblo. Un Monseñor distinto, desdibujado, aguado, sería irreconocible. $Y$ de él -la verdad- no habria mucha necesidad.

b) Relacionado con esto, es también peligroso que con ocasión del proceso de canonización la Iglesia repitiera, con cicrto exclusivismo, que "Monseñor 
Romero es nuestro", que "no nos dejemos arrebatar a Monseñor". Esto se decia antes - con algo de razón hasta cierto punto - para evitar que Monseñor fuese manipulado espúreamente. Pero no debiera prevalecer este enfoque exclusivista, y menos hoy. Monseñor Romero, como salvadoreño, como ser humano y como cristiano, es de todos. Si lo hacen con honradez, todos lienen derecho a invocarlo y a todos puede hacer un gran bien. Y lo empobrecedor de insistir en el "es nuestro" es que de esa forma a los oprimidos se les privaría de una esperanza y a los opresores se les ofrecería una excusa para no tener que imitarlo.

En este contexto es bueno recordar que cuando, pocos años después de su asesinalo, comunidades de base y organizaciones populares salieron a la calle superando el miedo a la represión de aquellos días- se oyeron voces que querían encerrar a Monseñor en el templo. Entonces, Ignacio Ellacuría escribió: "Bien está Monseñor en el templo, y bien está Monseñor en la calle. Que lo que Dios ha unido no lo separe el hombre".

Esto que hemos llamado "peligro" podría, quizás, aparecer en la redacción del acta de canonización, en qué de Monscñor Roncro se menciona en ella y qué —si algo- se calla de él. Pero, indudablemente, eso no es lo decisivo. Pasará el dia de su canonización y se olvidará cómo quedó redactada el acta. Lo decisivo está ocurriendo ahora, cuando se eslá fraguando la imagen de Monscnoor. Ya hay muchos análisis de su vida y su obra, y hay sobre todo la convicción de su realidad total como salvadoreño y cristiano. Así, en esa totalidad, lodo de Dios y todo de los pobres, Monseñor sigue siendo una buena noticia.

6. La canonización oficial de Monseñor Romero puede traer bienes muy grandes: confromarnos con muestra realidad, llamar a conversión, devolver dignidad a las víctimas, proclamar a América Latina continente mártir.

a) La canonización oficial de Monscñor puede ser una ocasión para repensar la realidad del pais. Recordar las víctimas y los verdugos de entonces puede llevar a analizar los de ahora, a tomar conciencia de la pobreza, la violencia y la injusticia actuales, y a buscar la dirección en que construir una socicdad justa. Puede llevar a repensar los errores de la impunidad y de las amnistias inconsultas y precipitadas, y a una buena administricación de justicia. Puede llevar —ojalá - a la conversión, cxigida y facilitada por la presencia de Monsenor Romero y de muchos otros mártires entre nosotros. (En la canonización de María Gorelli, asesinada al principio del siglo por no ceder ante quien la quería forzar, estuvo presente su asesino.) $Y$ puede llevar a comprender la necesidad de "revertir la historia". Todo esto es utópico. evidentemente, pero no deja de expresar bienes importantes y necesarios. Y una buena ocasión de propiciarlos sería la canonización de un mártir lipicamente salvadoreño, como Monseñor Ronicro. 
Más claramente, esta canonización puede llevar consuelo a muchísima gente, y sobre todo el sentimiento de que una institución importante, el Vaticano, y una persona importante, el Papa, "les dan la razón". No estaban ellos equivocados, Monseñor fue víctima y es santo. Y no es éste pequeño gozo para un pueblo que nada cuenta a la hora de decidir las cosas importantes y a quien no se suele preguntar su opinión sobre ellas.

Más específicamente, la canonización de Monseñor Romero devolverá dignidad a muchas otras víctimas, y con ello traerí hondo consuelo a sus seres queridos - lanto mayor cuanto que, al ser personas religiosas muchísimas de ellasesa dignidad viene ahora envuelta en lo sagrado de Dios. Recordémoslo. Monseñor Romero, y tantos otros, en vida fucron difamados y calumniados. Se les negó honradez y fe crisliana. Se les acusó, con mentira, de toda clase de aberraciones: "Monseñor Romero vende su alma al diablo", decia el titular de un periódico de la época. La Comisión de la Verdad fue sensible a esta aberración y exigió reparación a la dignidad de las víclimas. Puede ser que algún día se consiruya un monumento en su honor, pero, aunque así ocurra, una canonización es cosa distinta. Es Dios quien devuelve la dignidad. Y de esa dignidad que otorga la canonización de Monseñor participan todos los mártires.

En nuestra historia actual y concreta, la canonización de Monseñor Romero $-\mathrm{y}$, en él, la de muchos más- no tiene la estructura de "revancha", ni menos de "venganza". Pero sí tiene la estructura del Magnificat, el trastrueque que opera Dios: "A los pobres los llenó de bienes, y a los soberbios despidió vacíos". Y por ello, muchos salvadoreños - madres, sobre lodo- dirán: "Engrandece mi alma al Señor y se alegra mi espíritu en Dios mi salvador, porque ha puesto los ojos en la humildad de su esclava, por eso desde ahora todas las generaciones me llamarán bienaventurada".

b) Ya ha quedado insinuado, pero hay que explicitarlo. Monseñor Romero es un mártir conocido, quizás el más conocido, pero no es el único. Como Jesús en la Carta los lilebreos es el hermano mayor en una inmensa nube de tesligos. Esto quiere decir que el martirio en América Latina $\longrightarrow$ en amplias regiones de ella- ha supuesto una verdadera globalización.

Las instituciones mundiales —incluidas Naciones Unidas- no tienen interés en reconocer esta "globalización del martirio", por la incapcidad de sus mecanismos en dirimir estos asuntos y por las presiones políticas a las cuales suelen ceder. Pero bicn lo puede hacer la Iglesia calólica. $Y$ 一 soñando- quizás se puedan encontrar modos para que, de alguna manera, aunque sea simbólicamente, en esa canonización participasen todas las iglesias; y para que en la canonización de Monseñor se reconociese también, de alguna manera, a los innumerables mártires de América Latina y al inmenso y mártir mundo de los pobres.

Que se llegue a realizar esta ulopía es muy difícil, por supuesto. Pero es imporlante tener presente la identificación de Monseñor Romero con su pueblo, 
con las víctimas sobre todo, y en aquellos aspectos "martiriales" ya durante su vida. "Yo no quiero ninguna seguridad mientras no se la den a mi pueblo". Permílasenos la audacia, pero ¿no pudiera pensarse que Monseñor esté ahora diciendo "yo no quiero una canonización que no incluya la de mi pueblo?", aunque sea "de alguna manera", añadimos nosotros.

Dicho primero en forma negativa, esta canonización no debiera prescindir del contexto hislórico real: la abundancia de cristianos y de seres humanos a quienes se ha dado muerte por su amor y defensa de los pobres (los privilegiados de Dios), por su compromiso con la verdad y la justicia (reflejo en la historia del compromiso de Dios), y todo ello en muchos explícitamente, en otros anónimamenle, por la fe en uno, Dios, Padre y Misterio, y por el seguimiento humilde de Jesús. $Y$ no debiera olvidar las masacres de "santos inocentes", ancianos, niños y mujeres, asesinudos simplemente para facilitar la activiJad bélica. Esta realidad, que en América Latina es cuantilalivamele masiva, y cualitalivamente cruel y esperanzadora, a la vez, no debiera estar ausente al Canonizar a su símbolo real: Monseñor Romero.

Dicho en forma positiva, ahora que se globaliza la trivialización de la fe y la existencia. que se globaliza el consumismo y el egoísmo, que se globaliza el desprecio y la exclusión de centenares, si no de miles de millones de stres humanos, es muy importante apuntar a otro tipo de globalización: la de la verdad, del compromiso, del amor y de la ternura.

Al canonizar a Monscñor Ronero, y, simbolizados en él, a lodos los mírtires, la Iglesial puede ofrecer cse servicio a nuestro mundo. Ojalá que en la canonización de Monseñor Romero estén prescntes Ellacuría y Julia Elba, Monseñor Angelelli y los indígenas del Quiché, los niños de Somalia y de Ruanda, las madres de Timor del este y Bosnia. Ojalá esıć presente un continente mártir, los pueblos crucificados.

Y no hay aqui masoquismo. A una victima, a un mártir, Jesús. Dios le hizo justicia y lo resucitó de entre los muertos. De ellos es la esperanza. A los vivos queda la responsabilidad de trabajar para bajarlos de la cruz.

24 de mirzo de 1998. 